\title{
Understanding the Nature of Mentoring Experiences between Teachers and Student Teachers
}

\begin{tabular}{|r|l|}
\hline Journal: & International Journal of Mentoring and Coaching in Education \\
\hline Manuscript ID & IJMCE-04-2017-0028.R6 \\
\hline Manuscript Type: & Research Paper \\
\hline Keywords: & $\begin{array}{l}\text { mentoring, teachers, student teachers, critical constructivism, initial } \\
\text { teacher education }\end{array}$ \\
\hline \multicolumn{2}{|l}{} \\
\hline
\end{tabular}

SCHOLARONE

Manuscripts 


\section{Understanding the Nature of Mentoring Experiences between Teachers and Student Teachers}

\section{Purpose}

Mentoring is widely recognised as an effective strategy for supporting the professional learning of teachers and student teachers across different educational contexts. Yet, its effectiveness in initial teacher education may be more widely conceived to take account of mentoring as a cultural practice, contributing to a change of professional learning habits and relationships towards collegiate and collaborative reflexivity. In this study, we explored the nature of mentoring experiences between teachers and student teachers, how these are embedded within the established professional learning culture of the school and the opportunities for mentoring to affect professional learning.

\section{Design/Methodology/Approach}

Set within the context of a teacher education reform project in Scotland, involving student teachers, mentors and university tutors, the study adopted a critical constructivist theory stance to explore mentoring relationships. A sequential mixed methods approach informed the collection and analysis of data.

\section{Findings}

Quantitative data point to a diversity of experiences of mentoring amongst teachers and student teachers. Qualitative data provide a nuanced account of participants' views of their mentoring experiences, pointing to opportunities for revisiting assumptions about learning in the classroom as well as questioning established professional learning patterns.

\section{Practical Implications}


We conclude that mentoring relationships cannot be disentangled from a critical interrogation of the modes of relationships and values supporting professional learning in initial teacher education. Practical implications centre upon preparation and resources to develop mentoring as a tool for learning, embedded within the professional culture of the school.

\section{Originality/Value}

The study reframes the concept of mentoring as a practice that does not simply reinforce professional expectations but seeks to redefine teacher professional learning, pedagogy and social relationships in school contexts.

Keywords: mentoring, student teachers, teachers, critical constructivism, initial teacher education

\section{Introduction}

Mentoring is widely recognised as a strategy to promote professional learning in a variety of professional sectors (Aspfors and Bondas, 2013; Cosnefroy and Buhot, 2013; Kemmis et al., 2014; Menon, 2012; Trevethan, 2017). In teacher education, mentoring programmes have been introduced to enhance teachers' professional experiences at different stages of their career, provide on-going and site-specific support for teachers' professional development (Korhonen et al., 2017; Kougioumtzis and Patriksson, 2009; Menon, 2012) and increase the retention rates of beginning teachers (e.g. Koballa et al., 2010; Korhonen et al., 2017; Long, 2009; Menon, 2012). Mentoring in teacher education may contribute to enhancing both motivation and competence, with implications for the quality of young people's learning and development, globally (Peters, 2001; Tang et al., 2015). 
While mentoring in initial teacher education (ITE) is often portrayed as a dyadic and unidirectional relationship, involving mentors supporting mentees to reach their goals, the importance of creativity and collaboration amongst all participants involved in the learning process, such as children and/or other professionals in the school, has also been documented (Bradbury, 2010; Lofstrom and Eisenschmidt, 2009). Certainly, mentoring relationships between two people can be collaborative; however, such collaboration may be limited to specific goals and purposes, different from forging wider collaborative relationships which may bring potentially new practices into existing settings (Aderibigbe, 2013, 2014; Aspfors and Bondas, 2013; Kaasila and Lauriala, 2010; Menon, 2012). Hence, as recently indicated by Izadinia (2016), more research is needed to explore the extent and dimensions of collaborative mentoring experiences by focusing on the values and understandings of mentoring from the perspectives of teacher mentors and mentees.

Located within an ITE context in Scotland, this study sought to explore the nature of collaborative mentoring relationships and how such relationships may be related to different theoretical dispositions towards mentoring. The study is significant in that it contributes to the developing body of knowledge about mentoring practices in ITE by offering further insights into collaboration in mentoring and the implications for teachers' learning in professional contexts.

\section{Context}

A study of mentoring relationships between student teachers and mentors was particularly timely given the emphasis placed on mentoring practices in the Donaldson Review of Teacher Education in Scotland, published in 2010. Donaldson's review recognised the importance of mentoring, suggesting that it required "the redefinition of roles and responsibilities to include 
increased reflection, collaboration and partnership" (p. 48), but also noted that "levels of satisfaction with the quality of mentoring could be improved further" (p. 51). Such a view is mirrored in England with a recent House of Commons briefing paper on initial teacher training, stating, "Mentoring across England is not as good as it should be" (Roberts and Foster, 2017 p. 7). Donaldson also undertook a review of curriculum and assessment in Wales (Donaldson, 2015), which stressed the need to develop 'system capacity', through an extensive and sustained programme of professional learning.

In this regard, Mtika et al. (2014), reporting on a study about quality in teacher education in Scotland, remarked that teacher professional learning is grounded in productive partnerships, such as those between schools and universities. However, a gap in assumptions and expectations regarding priorities for teachers' professional development is often at the heart of practicum problems (Bain et al., 2017; Trevethan, 2017). So, one of the important aspects of the programme examined here, and which provided the context of this study, was the creation of a continuum of mentoring support for student teachers and beginning teachers spanning the undergraduate years and through to the first two years of induction and professional practice in schools. As explained in Korhonen et al. (2017, p. 154), the essence of the continuum approach is to "move away from over-emphasis on initial preparation by distributing teacher learning and professional development across career stages, and thus to support and promote the lifelong learning of teachers". Such a framework has been advocated by others as a core premise to enhance teachers' professional development (Geber, 2013; Hughes et al., 2013).

However, while the Donaldson Review (Donaldson, 2010) recognised that mentoring is essential for both new and experienced teachers, the translation of policy messages into practice 
is notably shaped by deeply seated cultural assumptions and expectations about the nature and practices of professional learning.

So, in the context of this study, mentoring was positioned as an integral aspect of teacher professional learning in a partnership context. As such, mentoring was not simply conceived of as a support mechanism for student teachers to become apprentices in schools, but as a framework for strengthening mutual learning, integrated within a critical constructivist approach, discussed later, which provided the basis for pedagogy and practice within and beyond ITE. The investigation centred upon the nature of the mentoring relationships enacted by student teachers and teacher mentors in the programme and the implications for professional learning.

\section{Theoretical Framework}

Mentoring is differently understood, conceptualised and theorised (Kemmis et al., 2014) across diverse professional contexts. These differences may lead to potential confusions, overlaps or 'borrowing' of approaches that are derived from a variety of disciplines supporting distinct practices. Kemmis et al. (2014) argued that what may be confusing about mentoring is not a lack of theories but rather the existence of a plurality of theories. They explained further that distinctive theoretical perspectives have been developed by scholars, each contributing selected aspects. Drawing on an extensive literature review, Wang and Odell (2007) identified three dimensions of mentoring: humanistic, situated apprenticeship and critical constructivist perspectives. While the humanistic dimension is largely centred upon the psychological and personal aspects, the other two perspectives offer more explicit cues on the nature of professional relationships. More specifically, Wang and Odell (2007) brought to surface the normative contexts in which professional relationships may develop, distinguishing between the 
bureaucratic-managerial and the participatory-involved approaches. The first scenario points to asymmetric relationships between mentor and mentee, on the basis of either power or expertise; while the second scenario emphasises mutuality and voice. When applied to the context of the classroom, the bureaucratic-managerial dimension locates student teachers in the role of 'visitors' in the school, who are expected to facilitate classroom activities as strictly instructed. This conception would align broadly with conceptions of mentoring as an apprenticeship process, where novice and student teachers are guided to develop professional knowledge by mature and experienced teachers (Aderibigbe, 2014; Hobson and Malderez, 2013; Wang and Odell, 2007). In the same vein, Maguire (2001, p. 99) acknowledged that the process "sounds a sensible and practical way in which to induct and support novice teachers". However, this author also noted that if mentoring is used as a means to induct beginning teachers into following standards, it may strain relationships and lead to situations where novice teachers may feel unwelcome or even bullied into conforming to an implicit model of what an ideal teacher should be like. Hobson and Malderez (2013) also reported that mentoring may hamper mentees' learning and professional development when mentors are judgemental while providing them with feedback on their practice.

Conversely, the participatory-involved process recognises the potential for student teachers to engage in joint decision-making with teachers about activities conducted both within the classroom and more widely in the school. Rather than focusing exclusively on the student teacher as a new learner, the participatory-involved process places emphasis on the quality of the learning environments for beginning teachers; such environments are deemed to be "empowering and enabling" by the extent to which they support mentees with opportunities to work together with others as well as develop skills to "do things for themselves" (Clutterbuck, 2004, p. 11). 
Trevethan (2017, p. 221) argued that the essence of this collaborative model "is an understanding that close relationships and collaboration are valuable for both teacher and student teachers' learning". The model is also consistent with the constructivist perspective of mentoring where mentors and mentees can learn from each other to strengthen their professional development (Aderibigbe, 2014; Bradbury, 2010; Wang and Odell, 2007).

Undoubtedly, a mentoring process guided by the apprenticeship disposition has its merits, in that student teachers can be inducted into school settings and assisted to understand the existing norms. However, it may not offer opportunities for student teachers to be creative and innovative if they have to comply with strict procedures (Shea, 2002). In contrast, Aderibigbe (2013) found that mentoring can be more beneficial and tends to encourage more creativity amongst mentors and mentees when characterised by dialogue and collaboration.

Taking these considerations into account, in this study we sought to further investigate the dimensions of collaborative mentoring in ITE, along with identifying factors contributing to their development. We draw upon earlier theoretical (Wang and Odell, 2007) and empirical (Aderibigbe, 2013) studies on mentoring as grounded in a critical constructivist approach, which is both participatory and collaborative in nature (Kemmis et al., 2014) and supported by an egalitarian structure for creating knowledge in context (Kincheloe, 2005). From this perspective, we recognise that mentoring is a multi-faceted and complex activity that is associated with some other forms of relationships such as coaching, facilitating, counselling, and networking (Landsberg, 1996). All such activities include different forms of collaborative learning amongst participants (Bradbury, 2010; Kutsyuruba, 2012), yet underlie the centrality of mutual respect and dialogue as key dimensions in collaborative mentoring. 
In this regard, Fieman-Nemsar (2001) warned that collaborative dialogue may be counterproductive if there is no room for the exploration of multiple standpoints. So, in the first instance, collaborative mentoring processes may be characterised by a joint effort between mentors and student teachers to examine pedagogical knowledge, share ideas and generate new professional knowledge (Hughes et al., 2013; Kincheloe, 2005; Kutsyuruba, 2012). Secondly, reflective practice, as it was first advanced by Schön (1983), can challenge the dominant technical-rational and positivist epistemological disposition which narrows down the opportunities for knowing and learning. Thirdly, practitioners involved in collaborative dialogues can challenge their own implicit understanding of what is deemed to be 'regular practice' to explore different forms of professional practice and learning. In this sense, mentoring based on the critical constructivist approach may blend guidance (that is given when necessary) with equal participation in class, including coordination between teachers and student teachers.

However, for a genuine collaboration informed by critical constructivist theory, mentors and student teachers need to be well disposed to the basic values and principles of professional collaboration (Hudson, 2013; Turner, 2013). For example, in this study, the term 'equal participation' is not used to suggest equality of status between experienced teachers and student teachers. Rather, it indicates equal participation where both teachers in the role of mentors and student teachers as mentees are empowered to collaborate actively and to contribute to effective teaching and learning. Consistent with this, Hobson and Malderez (2013) discussed at length the need for micro-level commitment through which mentors and mentees are open to learning from each other, valuing each other's knowledge, responsibilities, and contributions throughout the mentoring process. Paramount to the process of equal participation is clarity of beliefs and perceptions about mentoring (Lofstrom and Eisenschmidt, 2009; Wang and Odell, 2002), so that 
mentoring practices can be more evidently located within particular theoretical and normative orientations. For example, Long et al. (2012) explained that pre-service teachers might sometimes believe that good teachers should be able to teach alone, and that mistakes should be hidden in order to indicate effective performance. Being with somebody else in the classroom may thus be perceived as being uncomfortable or intrusive. Conversely, Aspfors and Bondas (2013) reported on the overwhelming feelings of anxiety and frustration when teachers operate at a distance from each other and in isolation. The transition to becoming a professional teacher would thus entail a strengthening of relationships through collaborative mentoring, allowing space for critical and creative dialogues.

In sum, drawing on the analysis of literature on mentoring, this study set out to examine the views of teachers (mentors) and student teachers (mentees) about their mentoring experiences, focusing on the nature and the extent of collaboration established between them and potentially with other relevant people, creating the conditions for extending professional dialogue (Bradbury and Koballa, 2008).

The following research questions guided the study:

i. To what extent is the mentoring experience defined as 'collaborative' in this context?

ii. What are the social, cultural and emotional factors shaping the nature of mentoring experiences in this context?

\section{Research Design}

We acknowledge that mentoring processes situated in the context of student teachers' school experience as suggested here are complex, dynamic, and multi-faceted. Participants may need to practice skills, interactions and dispositions which might be different from those enacted to 
support more conventional apprenticeship models. To try to capture the fluidity and variety of the social dynamics at play, a concurrent mixed methods design, informed by a pragmatic approach to knowledge, was adopted (Creswell and Tashakkori, 2007). The pragmatic paradigm holds that truth or reality is contingent upon the context inhabited by the participants and continuously constructed and reconstructed in the social world. Gray and Colucci-Gray (2010) argued that one single method or single paradigm may not be sufficient for research in conditions of complexity, as stakeholders may hold contrasting but valuable viewpoints. As such, it acknowledges the complex nature of research settings and the subjective views of participants (Berger and Luckmann, 1966; Creswell, 2003), particularly when researching changing relational dynamics which are shaped by socio-cultural practices and expectations. A mixed method approach was thus employed to provide a stepwise approach to the study, by charting in broad terms the areas of converging perceptions while teasing out factors and conditions accounting for what might have been different, personal experiences of mentoring in particular contexts.

\section{Context}

An important structural aspect of the teacher education programme supporting this investigation involved the incorporation of the mentoring process as part of 'field experience'; by this it was intended that student teachers would adopt an inquiry stance, by observing and interrogating their practices through reflection and professional learning conversations with their mentors as well as other members of the educational community based in school. In order to ensure that student teachers were fully supported while on school experience, mentors were invited to attend continuous professional development (CPD) programmes during which they were introduced to 
the philosophical principles of the programme and provided with a field experience handbook to support and guide student teachers on placement. During the training sessions, teachers had the opportunity to seek out clarification about different mentoring practices and expectations concerning school experience. University tutors also met with mentors at the training sessions to get to know each other and clarify mutual roles and expectations, in line with the partnership model of ITE established in Scotland (Mtika et al., 2014).

\section{Sampling}

For this study, participants were selected through a criterion sampling approach to identify cases and people that met set criteria of interest (Patton, 2002). We focused on student teachers who participated in field experience placements in Year 3 and Year 4 while enrolled in their undergraduate teacher education programme, as they were required to stay on field experience for a longer period of time; they were actively involved in teaching and they would therefore have the opportunity to enact long-term partnerships with their mentor teachers and potentially, others in school. Similarly, those mentors who worked with the student teachers were recruited as part of the study on the basis of their experience of mentoring. Finally, a group of university tutors who were involved in designing the practicum was purposively selected to provide contextual information about the programme principles and practices and thus provide additional insight into potentially contrasting approaches and theoretical dispositions to mentoring. Tables $1 \mathrm{a}$ and $1 \mathrm{~b}$ describe the demographic characteristics of the student teachers and mentors involved in this study.

$<$ Insert Table 1a here $>$ 
$<$ Insert Table $1 \mathrm{~b}$ here $>$

From Tables $1 \mathrm{a}$ and $1 \mathrm{~b}$, we note that gender distribution, heavily female dominated, is reflective of the general demographics of the teaching profession in Scotland. We also note that the majority of the mentors have more than 10 years' teaching experience, while the majority of the student teachers are in their early twenties. This suggests a significant age gap between them, which will be discussed later.

\section{Ethical issues}

Given the 'high stakes' involved in carrying out research at a time which is often stressful for student teachers, as well as for mentors who are involved in supporting them, we tried not to exceed demands on time by fitting in as much as possible with the regular routines of the programme (as will be explained later). Data were collected by the first author who was not a tutor and was not directly involved in the design of the programme, a position which enabled participants to feel free from any expectation to please either a colleague or their tutor. Participants were fully informed about the purpose of the study, and the ethical guidelines of the British Educational Research Association were followed to ensure their confidentiality and anonymity.

\section{Data collection: quantitative strand}

Questionnaires were first used to collect data from mentors $(\mathrm{n}=145)$ and student teachers $(\mathrm{n}=130)$ with a view to gaining baseline information for the more in-depth, qualitative analysis (Converse and Presser, 1986). The majority of Year 4 teacher mentors were able to attend one of the CPD sessions organised by the university and complete the questionnaire on site. The response rate 
was $80 \%$. Conversely, over $70 \%$ of the Year 3 mentors were not in attendance, so questionnaires were sent to all Year 3 mentors who did not attend the CPD event with a prepaid envelope and a covering letter to facilitate their response. The response rate for Year 3 mentor teachers remained high at $76 \%$.

For student teachers, both cohorts completed the questionnaires once they returned to university after their field experience. For Year 3 student teachers, the response rate was higher $(85 \%)$ than for Year 4 student teachers $(56 \%)$, potentially reflecting the added demands on Year 4 student teachers' time while in their final period of study at university.

\section{Qualitative strand}

Interviews were conducted with a small number of teachers $(n=6)$, student teachers $(n=7)$ and university tutors $(n=6)$, who were recruited by a voluntary expression of interest to be contacted for follow-up sessions. As Kvale and Brinkmann (2009, p. 1) explained, the interview "attempts to understand the world from the subjects' point of view, to unfold the meaning of their experiences, to uncover their lived world prior to scientific explanations".

A semi-structured interview was employed, which allowed the participants to express their views and experiences without any restriction (Patton, 2002). The interviews lasted 40 minutes on average, were recorded and subsequently transcribed verbatim.

\section{Data analysis}

Quantitative data and qualitative data were analysed separately. Quantitative data were analysed through descriptive statistics, while all qualitative data were reduced to manageable text through systematic coding. Data were then divided into chunks of coherent text aimed at answering specific questions related to the nature of collaborative relationships, after which consistent and 
shared ideas amongst the participants were developed as themes (Glaser and Strauss, 1967). We adopted a theoretically driven analysis, with themes emerging at the intersection of different theoretical approaches to mentoring, namely the bureaucratic-managerial and the participatoryinvolved, in order to uncover critical dimensions of power and expertise, as explained earlier. All the quantitative and qualitative data were then merged for interpretation and discussion of key findings.

\section{Findings}

\section{Quantitative Data}

The aim of the quantitative approach was to explore participants' perceptions of mentoring and factors regulating the nature of their mentoring experiences. Specifically, student teachers were invited to respond to options that described their mentoring experience and relationship with their mentors, while mentors were asked to indicate their willingness, preparation, and disposition to support student teachers.

As shown in Table 2, 75\% of student teachers stated that they had a good relationship with their mentors. Nineteen percent indicated that they had a fair relationship with their mentors, while only $5 \%$ of them pointed out that their mentoring relationship was not good. Further, the student teachers were asked to comment on whether they were able to achieve what they considered to be important aspects of teaching and learning through mentoring support. As can be seen in Table 2, 62\% indicated that they were able to achieve their expectations, while $30 \%$ said they were able to partially achieve their expectations and $6 \%$ felt they did not achieve their expectations at all. As we will discuss later through the qualitative analysis, students 'expectations ranged from having the opportunity to practice teaching (in line with the 
apprenticeship model) to hoping for a partnership with the teacher mentor and learn together (more in line with the dialogical approach). Hence it may be possible that the expectations of some students were easier to meet than those of others depending on the nature of the mentoring process.

$<$ Insert Table 2 here $>$

When considering the demographics of the mentors, we note that more than half of the mentors had over 10 years of teaching experience. A good number of them also attended the CPD events where they were able to gain knowledge about the programme and discuss their role as mentors in preparation for student teachers' field experience. Also, many of them (57\%) had recent experience of supporting student teachers. Mentors were asked to indicate their prior conceptions and feelings about mentoring, and the large majority was enthusiastic and considered it beneficial, as indicated in Table 3.

$<$ Insert Table 3 here $>$

The results obtained from the questionnaires suggest that this group of mentors was well disposed to the idea of providing mentoring support for student teachers. However, some student teachers described their mentoring relationships as fair and not good. From the data, we might speculate that those who had good mentoring relationships and achieved their expectations may have been paired with mentors who were passionate about mentoring and found it rewarding. Some of those mentors may also have given the student teachers the opportunity to be actively involved in decision-making during their placement, as per the critical constructivist approach to mentoring. Conversely, it may also be that student teachers who reported negative experiences did not find sufficient opportunities for discussing practice; and even in the context of being supported by an experienced teacher, their learning experience may have turned out to be more 
akin to training by instructions, rather than through socially constructed professional knowledge. The extent to which the relationships were influenced by the critical constructivist approach to mentoring cannot be clearly established at this level of analysis. Rather, a mixed scenario of approaches to mentoring was to be expected and was further explored in the qualitative data.

\section{Qualitative Data}

The qualitative data provide a more nuanced picture of the mentoring process and the factors responsible for the experiences described by the participants in this study. Three categories of mentoring relationships emerged as illustrative of the different forms of collaboration through mentoring in the classroom.

\section{Collaborative relationships}

Some of the evidence obtained from the interviews gives indication of collaborative relationships enacted in the classroom:

We sort of plan each week together and sort of share for example, this time our topic is save the world so we shared what we would do within that topic. (Mentor 2)

It was quite a partnership because she would include me in what she was doing as well when she had the class, so that was good. (Year 3 Student Teacher 2)

From the data, we can infer a sense of satisfaction expressed by these participants, as though the idea of a collaborative mentoring relationship fitted in with a set of mutually shared expectations. A collaborative mentoring relationship in this case was developing alongside a form of participatory pedagogy. Similarly, this type of collaborative practice may suit a process of sustained and constructive debriefing, as commented by one student teacher: 
She would have time for me to sit down and if after I'd taken a lesson and she'd been there, she would always tell me kind of little positive things about what I was doing. (Year 4 Student Teacher 2)

Interestingly, in the quotation above, critique is offered within a climate of support. The mentee is not simply pointing to the value of gaining feedback on practice but also on the value of "being there', making time for talking. A tutor also acknowledged positive transformation in student teachers' work and behaviour because of mentoring support:

The kind of work that they're producing and the way that they're behaving when they're in school, has got better. (Tutor 2)

This finding suggests that collaborative mentoring relationships experienced by some participants in this study featured specific activities that align with critical constructivism. These activities include co-planning, co-teaching and cooperation between mentors and mentees in the classroom.

\section{Different interpretations of collaborative relationships}

Mentoring relationships were said to be collaborative as well as non-collaborative at other times, for example as mentioned by those participants who found it difficult to 'feel part' of the professional team:

We were able to almost team teach in the second part, whereas in the first part, there wasn't a lot of collaboration there. I felt like I was on my own for quite a lot of it, there was not much collaboration there (B.Ed. 3 Student Teacher 4)

\footnotetext{
A mentor also suggested that collaboration between student teachers and mentors needs to take place, but not in all circumstances:
} 


\section{I think you need to collaborate sometimes in the classroom. (Mentor 1)}

The mentor's view might also be an indication that it is important to collaborate at various levels and in relations to various tasks, including sometimes in the classroom. Similarly, a tutor felt that collaborative relationships are noticed, but it may be difficult for such relationships to be enacted in all situations:

I think in the majority of cases that's working well. But I think, we'll never get to that point where we can say it's working in every case. (Tutor 2)

This data suggests that there are constraints on collaboration which may be why some of the participants maintained that their expectations were not fully accomplished:

In the second half, I think they were met. However, I don't think my expectations and my mentor's expectations were the same in the first half. (Year 3 Student Teacher 4)

These findings suggest that there existed a mixed and inconsistent scenario regarding the purpose and practices of mentoring relationships in this context. Most importantly, what appears to be foregrounded in participants' voices is the nature of professional learning that in some instances was not deemed to be enacted as a team approach. Rather, for some people, professional learning was either 'acquired/enacted' or 'yet to be acquired/not enacted', a dichotomy which sets a stark separation between professional experts and novices. Arguably, such dichotomy may be at the heart of student teachers' inability to feel 'inducted' and 'mentored' into a professional learning culture. In such situations, the professional learning culture is one of 'quiet acceptance' and endurance, with limited scope for critical appraisal, mutual reflection, and dialogue.

Non-collaborative relationships 
One of the tutors pointed to the need to acknowledge power in the classroom. This aspect is important when it comes to practice, for the student teachers need to feel able to take responsibility for their actions, while emphasising the role of mentors in monitoring and giving regular feedback to student teachers.

I would say however that there is an essential handover phase where the mentor has got to handover their class perhaps, to the student teacher, and they've got to signal trust.

\section{(Tutor 5)}

Such notion of transfer of power is problematic for some teachers who may feel that they have to leave the class outright and thus forfeit their role of experienced professional and observer of student teachers:

She wasn't in the classroom that much. (Year 4 Student Teacher 1)

For this reason, some student teachers did not feel that collaboration occurred, even though in appearance they had the opportunity 'to practice teaching', as per traditional models of learning to teach. One student teacher explained,

I haven't really seen much co-teaching in practice and because we didn't really do it on placement, it was either her there or me there. (Year 4 Student Teacher 2)

Furthermore, some student teachers explained that they preferred to take the class alone because of a lack of clarity regarding their dual and mutual roles in the classroom:

I felt a bit like I had to establish my own identity with them, so if we were both in the classroom, I didn't really know what my place was, so I preferred to either take a group out separately or have the class to myself. (Year 4 Student Teacher 2)

Another student teacher explained that while she preferred to take the class alone, she would find it valuable to have the chance to be 'checked in' by the mentor once in a while. Without this 
exchange, she believed, her professional learning remained unchallenged and pupils' educational interest may have been at a risk:

If I'm honest, there were a few times that I just gave them something a bit easier to mull over instead of getting to know what I should be doing to help them move onto the next step. (Year 4 Student Teacher 1)

All this suggests that student teachers' expectations of some aspects of their mentoring relationships were variable. Additionally, a student teacher thought it was a mark of respect not to be involved in classroom activities when a mentor is in control:

I didn't want to impact too much on like behaviour management when she was in control of the class, 'cos then they might have felt like oh, I'm taking it away from the class teacher. (Year 3 Student Teacher 2)

Probing further, it appears that this student teacher's decision not to collaborate with another teacher was rooted in previous experience. When she once tried to assist with the coordination of pupils' activities, the deputy teacher supporting her in class in the absence of her mentor was not well disposed to that approach:

After the lesson, she just said I prefer if you didn't do that, because some colleagues might not appreciate it. (Year 3 Student Teacher 2)

This finding may contribute to explain the reasons why some participants felt it would be fair to suggest that they did not achieve their expectations. As expressed more clearly by another student teacher,

I think if I was to have a mentor who was supportive in letting me do the ways that I would like to be as a teacher, then my expectations would be great of that placement. (Year 3 Student Teacher 1) 
Generally, these findings seem to echo previous studies reporting that collaborative mentoring, which involves sharing of power and redefinition of roles in the classroom, may be challenging and difficult to enact. Interestingly, hindering factors seem to include structural and cultural arrangements within the hosting school as per "some colleagues might not appreciate it" (Year 3 Student Teacher 2). Indeed, there seems to be confusion about the roles that mentors and student teachers can play in the same classroom and the nature of the pedagogy that may support collaborative and critically constructivist approaches.

\section{Discussion}

This study explored the nature of mentoring experiences between teachers and student teachers in an ITE context. Two research questions guided the investigation. In the first instance, the study considered dimensions of collaboration in mentoring relationships, which in this research context, was mainly conceived of as a dyadic interaction, amenable to study through an exploration of perceptions of mentoring held by teachers and student teachers. Drawing on the literature on mentoring (i.e. Wang and Odell, 2002; Hobson and Malderez, 2013), the argument for collaboration is an important one but one which relies upon the values and attitudes of teachers and student teachers. Hence, the second research question underscored the social, cultural, and emotional factors underpinning collaboration. The study was focussed on furthering understanding of the extent to which mentoring relationships enable space for inquiry, within an ethos of participation, this being the basis for more expansive forms of collaboration which may involve other people, pupils and colleagues, in the school. We will deal with each aspect in turn. Generally, findings show that mentoring between teachers and student teachers appears to be characterised largely by collaboration, which was taken as a grounding principle of the new 
programme. From the data, a collaborative mentoring experience is exemplified by joint decision-making and debriefing undertaken by mentors and student teachers who are actively involved in planning and teaching activities. For instance, one student teacher explained that he was involved in decision making process in the class. Similarly, Year 4 Student Teacher 2 indicated that her mentor would always sit with her to provide her with constructive feedback on how she could improve after she had taken a lesson. Debriefing is considered an important element of the scaffolding process in the mentoring relationships enacted in this context. This finding may explain why $75 \%$ of student teachers thought their mentoring relationships were good, and $65 \%$ felt they were able to achieve their expectations. Kincheloe (2005) contended that critical constructivism strives for egalitarian approaches to create professional knowledge in a context. Thus, our findings suggest that mentoring relationships based on joint decision-making are essential not only for effective teaching and learning but also reinforcing previous studies affirming that teachers and student teachers can learn from each other to further develop their professional knowledge and skills through mentoring processes (Aderibigbe, 2013; Hughes et al., 2013; Kemmis et al., 2014; Margolis, 2007).

However, it is important to note that the enactment of genuine collaboration in mentoring is influenced by people's knowledge, experiences and dispositions (Hudson, 2013; Trevethan, 2017; Wang and Odell, 2002). As revealed in our quantitative data, $71 \%$ of the teachers were looking forward to mentoring student teachers, and $51 \%$ also perceived such an endeavour to be beneficial. In addition, the data suggest that most teachers involved in this study were willing to engage in collaborative activities with student teachers. Consistent with this, Lopez-Real and Kwan (2005) advised that teachers involved in a mentoring process must be intrinsically stimulated to support others. Not surprisingly, Tutor 3 explained, "The willingness to collaborate 
is there, so that's been impressive". This finding highlights the importance of the experience of mentors in a particular context for effective mentoring relationships to take place (Kanan and Baker, 2002; Lofstrom and Eisenschmidt, 2009). Arguably, in the educational context, a commitment to sharing knowledge and practices is of uttermost importance, as findings underscore the need for mentors and student teachers to engage actively in collaborative investigations in order to better understand what may be different teaching and learning needs (Lofstrom and Eisenschmidt, 2009; Schön, 1987; Wang and Odell, 2002). However, an overemphasis on professional consensus may stifle professional learning. Hence, a critical perspective on mentoring would encourage experienced teachers to engage in bilateral dialogues with respect for multiple viewpoints (Fieman-Nemsar, 2001), while student teachers would need to demonstrate their commitment to learning from others through mentoring (Hobson and Malderez, 2013). Such dispositions are deemed to strengthen collaboration and can help to avert the mentoring relationship from becoming a bullying exercise as described by Maguire (2001) or a judgemental process (Hobson and Malderez, 2013).

That said, there were significant differences in the way mentors set out the ground rules for their engagement with student teachers on placement. While collaboration may be said to exist at least in principle in some cases, mentoring relationships could be significantly different in relation to professional learning practices. For instance, our data pointed to constraints on collaboration, indicating that collaboration may be seen as a task, enacted for some purpose, as opposed to being a guiding principle for professional and pedagogical practice. Moreover, there may be important differences in the professional learning ethos guiding teachers working with different groups of pupils. As our qualitative data revealed, some student teachers had a collaborative experience at some stages and felt like outsiders at other stages. 
Hence, such findings would also suggest that, to some participants, collaboration is neither consistently nor deeply rooted in critical constructivist values such as egalitarianism, colearning and co-participation (Hughes et al., 2013; Kincheloe, 2005; Kutsyuruba, 2012; Trevethan, 2017). Perhaps this explains why $19 \%$ of the student teachers felt they only had 'fair' relationships with their mentors (Table 2). Findings underscore the need for clarity about concepts used in mentoring relationships (Aderibigbe, 2013) to avoid a state of confusion as explained in Kemmis et al. (2014).

Finally, the data also show that mentoring experiences of some participants could only be described as non-collaborative. From the questionnaires, it transpires that some teachers did not look forward to supporting a student teacher (7\%) and some of them also considered it to be an imposition. Not surprisingly, a student teacher explained that her mentor "wasn't in the classroom that much" (Year 4 Student Teacher 1). Enactments of non-collaborative mentoring, however, may not be due to factors peculiar to the mentors alone. Some student teachers were not willing to collaborate with mentors in the classroom, perhaps because they felt that qualified teachers need to teach alone (Long et al., 2012). Such beliefs are common, as for most student teachers the image of a professional teacher is foregrounded as the sole figure responsible for learning in the class; yet Aspfors and Bondas (2013) reported that teaching is a profoundly collegiate activity, with feelings of anxiety and frustration commonly reported when teachers are at a distance from each other. Thus, it seems essential to note that even though student teachers would learn from having to coordinate class activities alone, it is necessary for them to learn from others. As the data also indicate, the presence of teachers in the class could aid student teachers' learning. 
In practice, findings seem to point to the need to revisit mentoring beyond dyadic interactions directed towards the achievement of specific objectives or goals. A key aspect in this process is the importance of sustained engagement between ITE providers and schools in trying to clarify what collaboration in mentoring between teachers and student teachers really entails, such as seeing mentoring as part of an expansive professional learning culture which includes other people, colleagues, and pupils, and which is extending across the professional learning space. Such ideals, however, need to contend with the practicalities of teachers attending professional development sessions, which are vital in enabling teachers to gain preparation for students' field experience (Hudson, 2013; Wang and Odell, 2002). As indicated earlier, some mentors (28\%) were unable to attend the events in preparation for student teachers' field experience, and this may have contributed to their inability to support and work collaboratively with student teachers. Professional development activities and information sessions held in the evening would in fact impact teachers' own personal schedules, which raise some new and unexpected dimensions of the study. For example, there is scope here for designing and researching models of professional development for teachers which may be better suited for introducing new practices in mentoring.

Strengthening understanding of mentoring in ITE would also encompass the need for further clarity regarding different orientations to mentoring and how these may relate to an inquiry-based, exploratory approach in student teachers' field experience. In this view, it is important to distinguish between the micro-level of action in the classroom (e.g. co-teaching, coplanning) and the meso-level of collaboration such as sharing values, principles, and ideas. We suspect that these levels may be interrelated. For example, co-planning may lead to a discussion of principles and values; however, it may not necessarily be so if an idea of learning to teach as a 
craft comes to dominate. In this scenario, collaboration may be reduced to handing over information to put into practice, and dialogue restricted to supervision enacted by the expert on the novice. The different scenarios for mentoring relationships highlighting the intersection between professional learning and socio, cultural and emotional dimensions as they emerged as part of this study, are summarised in Table 4.

\section{$<$ Insert Table 4 here $>$}

Relating common mentoring practices to social, cultural and emotional dimensions of professional learning, as summarised in Table 4, was the focus of our second research question, seeking to contribute further clarity about the role of mentoring in ITE. As indicated earlier, mentoring in teaching practice is fraught with difficulty for both student teachers and teachers and even more so due to the overlap between the dual roles of teachers serving as mentors, being both and at one time sharing ideas with the student teacher and taking responsibility for what happens in their own classroom. Findings from this study, however, clearly show that being a mentor who effectively meets student teachers' learning expectations is more than just providing student teachers with instructions or feedback on given practice. Mentoring is foregrounded as an embodied and deeply emotional practice, involving the ability to make oneself receptive to others, as well as being able to exert self-control when necessary, in order to allow for innovation and new perspectives which may emerge via mutual trust. While limited in scope, evidence from this study suggests that such personal qualities of collaborative mentoring may surface through specific pedagogies, hence the need to look further into ways of teaching that encourage critical, constructivist practices. For example, Table 4 highlights different approaches to mentoring student teachers in the classroom. Amongst those, our data point to practices which encourage sharing and acceptance of other people's ways of being as conducive to viewing the classroom as 
a genuine site of inquiry, yielding opportunities for questions, development of new practices and evaluation.

Most notably, this study suggests that such characteristics of mentoring, as dialogical, embodied and emotionally aware, when deployed in an educational context, can prepare the ground for the creation of sustained dialogical spaces, involving all partners and extending across the continuum of relationships amongst teacher educators, student teachers, mentor teachers and their colleagues (Mtika et al., 2014). This aspect is critical to teachers' professional development, but it is also critical in understanding how to build 'system capacity' (Donaldson, 2015) and the dilemma of partnerships between ITE providers and schools (Bain et al., 2017; Trevethan, 2017).

\section{Conclusion}

As evidenced in the discussion, findings from this study echo previous studies found in the literature which highlighted opportunities and challenges of mentoring in ITE. Adding to previous research, emphasis in this study was placed upon an established model of partnership aiming to support student teachers' learning through their experiences in the 'field'. So, broadly defined, the field would necessarily entail deeply seated cultural and professional norms that account for a diversity of working practices and relationships in every school. As our data show, collaboration took different forms in practice, and establishing consistent learning practices was difficult to do within the narrower boundaries of the classroom. Hence, the key message that this study wishes to put forward concerns the recognition of mentoring as a multi-faceted activity, but most centrally, that mentoring may be both a process leading to an outcome (e.g. practising a skill) and an opportunity to develop new positions on knowledge, by engaging with learning 
from others, as well as helping others to learn. In this view, dialogues between all parties involved in supporting student teachers should aim at building relationships, sharing ideas and developing shared understandings, moving well beyond the confines of the classrooms.

In Scotland, the Donaldson Review (Donaldson, 2010) is still providing the hallmark policy for high-quality teacher education grounded in strong mentoring practices. Policy is a significant factor in orienting teacher professional development and research towards collaborative mentoring. Currently, however, significant changes in the policy context in Scotland are shifting the focus from teacher professional learning to 'closing the attainment gap' for pupils. Substantial funding is being redirected towards schools, yet with unclear links to the nature and quality of the education of teachers (Bain et al., 2017; Seith, 2017). This study responds to such most recent policy by reiterating the need for a strongly collaborative and critical constructivist approach to mentoring if we are to educate and develop the type of teachers, both pre-service and in-service, and pupils who can respond to the complexities and uncertainties of current times. Further research should focus more directly on exploring the links between mentoring and the development of dialogical and inclusive pedagogies; for example, a longitudinal or ethnographic approach may be devised to explore the nature of mentoring relationships vis-à-vis the attainment gap. Scotland still has a chance to focus on mentoring and collaborative inquiry as a means to strengthen a critically reflexive professional culture.

\section{References}

Aderibigbe, S.A. (2013). Opportunities of the collaborative mentoring relationships between teachers and student teachers in the classroom: The views of teachers, student teachers and university tutors. Management in Education, 24 (2), 70-74 
Aderibigbe, S.A. (2014). Collaborative mentoring pedagogy in initial teacher education: Lessons from a Scottish context. In J. Cheryl and L. Orland-Barak (Eds.), International Teacher Education: Promising pedagogies (Part A) (Advances in Research on Teaching, Volume 22) (pp. 383-401). United Kingdom: Emerald.

Aspfors, J. and Bondas, T. (2013). Caring about caring: newly qualified teachers' experiences of their relationships within the school community. Teachers and Teaching: theory and practice, 19 (3), 243-25.

Bain, Y., Bruce, J. and Weir, D. (2017). Changing the landscape of school/university partnership in Northern Scotland. Professional Development in Education, 43 (4), 537-555.

Berger, P. and Luckmann, T. (1966). Social Construction of Reality. England: Penguin Books Ltd.

Bradbury, L. U. (2010). Educative Mentoring: Promoting Reform-Based Science Teaching Through Mentoring Relationships. Science Education, 94 (6), 1049-1071.

Bradbury, L.U. and Koballa JR., R.T. (2008). Borders to cross: identifying sources of tension in mentor-intern relationships. Teaching and Teacher Education, 24 (8), 2132-2145.

Clutterbuck, D.C. (2004). Everyone Needs a Mentor: Fostering Talent in Your Organisation, Chartered Institute of Personnel and Development, London

Converse, J.M. and Presser, S. (1986). Survey Questions: Handcrafting the standardized questionnaire, Sage series, No 63. Thousand Oaks, CA: Sage Publications.

Cosnefroy, L. and Buhot, E. (2013). Workplace learning impact: an analysis of Frenchsecondary-trainee teachers' perception of their professional development. Teachers and Teaching: theory and practice, 19 (6), 679-694. 
Creswell, J.W. (2003). Research Design: Qualitative, Quantitative, and Mixed Methods Approaches (Second Edition). California: Sage Publications.

Creswell, J.W. and Tashakkori, A. (2007). Editorial: Differing perspectives on mixed methods research. Journal of Mixed Methods Research, 1(4), 303-308.

Donaldson, G. (2010). Teaching Scotland' Future - Report of a review of teacher education in Scotland. Edinburgh: Scottish Executive. Available: http://www.scotland.gov.uk/Resource/Doc/337626/0110852.pdf (Accessed on 20/04/2011).

Donaldson, G. (2015). Successful futures. Independent review of Curriculum and Assessment arrangements in Wales. OGL.

Fieman-Nemsar, S. (2001). From preparation to practice: designing a continuum to strengthen and sustain teaching. Teacher College Record, 103 (6), 1013-1055.

Gray, D. S. and Colucci-Gray, L. (2010).'Challenges to ITE research in conditions of complexity'. Journal of Education for Teaching, 36 (4), 425- 439.

Geber, H. (2013). Can mentoring decrease the brain drain of academics from Africa? Procedia Social and Behavioral Sciences, 93, 215-220.

Glaser, B. G., and Strauss, A. L. (1967).The Discovery of Grounded Theory: Strategies for Qualitative Research. Chicago: Aldine Publishing Company.

Hobson, A. J. and Malderez, A. (2013). Judgementoring and other threats to realizing the potential of school-based mentoring in teacher education. International Journal of Mentoring and Coaching in Education, 2(2), 89-108.

Hudson, P. (2013). Strategies for mentoring pedagogical knowledge. Teachers and Teaching: theory and practice, 19 (4), 363-381. 
Hughes, M.T., Parker-Katz, M. and Balasubramanian, A. (2013). Learning to teach literacy through collaborative discussions of student work. Teachers and Teaching: Theory and Practice, 19 (5), 543-558.

Izadinia, M. (2016). Student teachers' and mentor teachers' perceptions and expectations of a mentoring relationship: do they match or clash? Professional Development in Education. $42(3), 387-402$

Kaasila, R., \& Lauriala, A., (2010). Towards a collaborative, interactionist model of teacher change. Teachers and Teaching, 26 (4), 854-862.

Kanan, H.M., and Baker, A.M. (2002). Palestinian Novice Teachers' Perception of a Good Mentor. Journal of Education for Teaching, 28 (1), 35-43.

Kemmis, S., Heikkinen, H.L.T., Fransson, G., Aspfors, J. and Edwards-Groves, C. (2014). Mentoring of new teachers as a contested practice: Supervision, support and collaborative self-development. Teaching and Teacher Education. 45, 154-164.

Kincheloe, J.L. (2005). Critical constructivism. New York: Peter Lang Publishing.

Koballa JR., T.R., Kittleson, J., Bradbury, L.U., \& Dias, M.J. (2010). Teacher Thinking Associated with Science-Specific Mentor Preparation. Science Education, 94(6), 10721091.

Korhonen, H., Heikkinen, H.L.T., Kiviniemi, U. and Tynjala, P. (2017). Student teachers' experiences of participating in mixed peer groups of in-service and pre-service teachers in Finland. Teaching and Teacher Education, 61, 153-163.

Kougioumtzis, K. and Patriksson, G. (2009). School-based teacher collaboration in Sweden and Greece: formal cooperation deprivatized practices and personalized interaction in primary and lower secondary schools. Teachers and Teaching, 15 (1), 131-154. 
Kutsyuruba, B. (2012). Teacher induction and mentorship policies: the pan-Canadian overview. International Journal of Mentoring and Coaching in Education, 1 (3), 235-256.

Kvale, A. and Brinkmann, S. (2009). Interviews (Second Edition) - Leaning the craft of qualitative research interviewing. Thousand Oak CA: Sage Publications Inc.

Landsberg, M. (1996) The Tao of Coaching: Boost Your Effectiveness at Work by Inspiring and Developing Those Around You. Harper Collins, London.

Lofstrom, E. and Eisenschmidt, E. (2009). Novice teachers' perspectives on mentoring: The case of the Estonian induction year. Teaching and Teacher Education, 25 (5), 681-689.

Long, F., Hall, K., Conway, P. and Murphy, R. (2012). Novice teachers as 'invisible' learners, Teachers and Teaching: Theory and Practice, 18 (6), 619-636.

Long, J. (2009). Assisting beginning teachers and school communities to grow through extended and collaborative mentoring experience. Mentoring \& Tutoring: Partnership in Learning, 17 (4), 317-327.

Lopez-Real, F. and Kwan, T. (2005). Mentors' perceptions of their own professional development during mentoring. Journal of Education for Teaching, 31 (1), 15-24.

Maguire, M. (2001). Bullying and the Postgraduate Secondary School Trainee Teacher: an English case study. Journal of Education for Teaching, 27 (1), 95-109.

Margolis, J. (2007). Improving relationships between mentor teachers and student teachers: Engaging in a pedagogy of explicitness. The New Educator, 3 (1), 75-94.

Menon, M.E. (2012). Do Beginning Teachers Receive Adequate Support from Their Headteachers? Educational Management Administration \& Leadership, 40 (2), 217-231. 
Mtika, P., Robson, D. and Fitzpatrick (2014). Joint observation of student teaching and related tripartite dialogue during field experience: Partner perspectives. Teaching and Teacher Education, 39, 66-76.

Patton, M.Q. (2002). Qualitative Research and Evaluation Methods (3rd Edition). Thousand Oaks: Sage.

Peters, M. (2001). National education policy constructions of the 'knowledge economy': Towards a critique. Journal of Educational Enquiry, 2(1), 1-22.

Roberts, N. and Foster, D. (2017). Initial teacher training in England. Briefing Paper, Number 6710.House of Common Library.

Shea, G.F. (2002). Mentoring (How to Develop Successful Mentor Behaviours), Third Edition. California: Crisp Publications Inc.

Seith, E. (2017). New route into teaching in Scotland could bypass universities. Times Education Supplement, $2^{\text {nd }}$ June 2017.Available at: https:/www.tes.com/news/schoolnews/breaking-news/new-route-teaching-scotland-could-bypass-universities

Schön, D.A. (1983). The reflective practitioner - How professionals think in action. London: Maurice Temple Smith Limited.

Tang, S.Y.F., Wong, A.K.Y., \& Cheng, M.M.H. (2015). The preparation of highly motivated and professionally competent teachers in initial teacher education. Journal of Education for Teaching, 41 (2), 128-144.

Trevethan, H. (2017). Educative mentors? The role of classroom teachers in initial teacher education. A New Zealand study. Journal of Education for Teaching. 43(2), 219-231.

Turner, M. (2013). Beyond the 'good teacher': guiding pre-service teacher reflections on culturally diverse students. Teachers and Teaching: Theory and Practice, 19 (1), 78-92. 
Wang, J. and Odell, S.J., (2002). Mentored Learning to Teach According to Standards-Based Reform: A Critical Review. Review of Educational Research, 72(3), 481-546.

Wang, J. and Odell, S. J. (2007). An alternative conception of mentor-novice relationships: learning to teach in reform-minded ways as a context. Teaching and Teacher Education, 23(3), 473-489.

\begin{abstract}
Author Biographies
Semiyu Aderibigbe completed his PhD study in the School of Education at the University of Aberdeen, United Kingdom. Currently, Semiyu teaches in the General Education Department, Mount Royal University (Canada) and the School of e-Education at Hamdan Bin Mohammed Smart University (UAE). His research interests include mentoring and peer coaching, critical constructivist pedagogy, teacher education, citizenship education, educational leadership and blended learning.
\end{abstract}

Donald Gray is a reader in the School of Education at the University of Aberdeen. Formerly a biology teacher, he has a background in science education, curriculum development and educational research. Donald's research focuses on science and sustainability issues, environmental education and outdoor learning as well as more general research related to teacher education.

Laura Colucci-Gray is a senior lecturer in Science Education and Sustainability Education in the School of Education at the University of Aberdeen. Laura holds a first degree in natural sciences awarded and a doctorate in science education. Her research is located at the intersection between 
teacher education, pedagogical innovation and the epistemological reflection on science, particularly with regard to the field of science technology studies and sustainability debates. 
Table 1a: Demographic characteristics of the student teachers $(\mathrm{n}=130)$

\begin{tabular}{|l|l|c|c|}
\hline \multirow{4}{*}{ Distribution of } & & \\
\hline \multirow{5}{*}{ Gender } & Male & Participants & Percentage \\
\cline { 2 - 4 } & Female & 5 & 4 \\
\cline { 2 - 4 } & Not stated & 124 & 95 \\
\hline \multirow{3}{*}{ Age } & $20-24$ & 1 & 1 \\
\cline { 2 - 4 } & $25-29$ & 106 & 82 \\
\cline { 2 - 4 } & 30 and above & 12 & 9 \\
\hline
\end{tabular}

Table 1b: Demographic characteristics of mentors ( $\mathrm{n}=145)$

\begin{tabular}{|l|l|c|c|}
\hline \multirow{4}{*}{ Distribution of mentors by } & & \\
\hline \multirow{4}{*}{ Gender } & Male & Participants & Percentage \\
\cline { 2 - 4 } & Female & 6 & 4 \\
\cline { 2 - 4 } & Not stated & 138 & 95 \\
\hline Qualification & First Degree & 1 & 1 \\
\cline { 2 - 4 } & Postgraduate Diploma & 32 & 46 \\
\cline { 2 - 4 } & Master's Degree & 17 & 22 \\
\cline { 2 - 4 } & Others & 19 & 12 \\
\cline { 2 - 4 } & Not stated & 10 & 13 \\
\hline Yeaching & $1-5$ & 27 & 19 \\
\cline { 2 - 4 } experience & $6-10$ & 25 & 12 \\
\cline { 2 - 4 } & $11-15$ & 17 & 13 \\
\cline { 2 - 4 } & $16-20$ & 19 & 35 \\
\cline { 2 - 4 } & 20 and above & 51 & 4 \\
\cline { 2 - 4 } & Not stated & 6 & 12 \\
\hline
\end{tabular}

Table 2: Student teachers' views on their mentoring relationships and expectations $(\mathrm{n}=130)$

\begin{tabular}{|l|l|c|c|}
\hline \multicolumn{2}{|l|}{ Student teachers' views: } & Participants & Percentage \\
\hline Mentoring relationships with their mentors & Good & 98 & 75 \\
\hline
\end{tabular}


Table 3: Mentors' views about mentoring and CPD attendance $(\mathrm{n}=145)$

\begin{tabular}{|c|c|c|c|}
\hline Mentors' views: & & Participants & Percentage \\
\hline How they felt about supporting & I look forward to it & 103 & 71 \\
\hline student teachers & I think it would be beneficial & 78 & 54 \\
\hline & I do not look forward to it & 10 & 7 \\
\hline & $\begin{array}{l}\text { I do not see myself as } \\
\text { somebody who can support } \\
\text { the student teachers }\end{array}$ & 10 & 7 \\
\hline & I feel it is an imposition & 1 & 1 \\
\hline Experience of supporting a student & Yes & 83 & 57 \\
\hline teacher in the past five years & No & 60 & 41 \\
\hline & Not stated & 2 & 1 \\
\hline Attendance at the CPD event in & Yes & 103 & 71 \\
\hline preparation for the student & No & 41 & 28 \\
\hline teachers' field experience & Not stated & 1 & 1 \\
\hline
\end{tabular}


Table 4: Summary of dimensions of collaboration in mentoring

\begin{tabular}{|l|l|l|}
\hline $\begin{array}{l}\text { Features of classroom } \\
\text { practice }\end{array}$ & $\begin{array}{l}\text { Type of mentoring } \\
\text { relationship }\end{array}$ & $\begin{array}{l}\text { Socio-emotional dimensions } \\
\text { of professional learning }\end{array}$ \\
\hline $\begin{array}{l}\text { Handing over the class and } \\
\text { providing feedback }\end{array}$ & Expert/novice & Control and alienation \\
\hline $\begin{array}{l}\text { Selection of practical } \\
\text { activities, such as joint } \\
\text { planning and coordination of } \\
\text { classroom activities }\end{array}$ & Master/apprentice & Instruction and guidance \\
\hline $\begin{array}{l}\text { Open tasks, inviting } \\
\text { contributions from others, } \\
\text { and including debriefing }\end{array}$ & Collegiate & $\begin{array}{l}\text { Participation and } \\
\text { legitimisation }\end{array}$ \\
\hline $\begin{array}{l}\text { Positive dispositions towards } \\
\text { learning with others }\end{array}$ & Peer support & $\begin{array}{l}\text { Equal participation and } \\
\text { mutual support }\end{array}$ \\
\hline $\begin{array}{l}\text { Close presence and empathy, } \\
\text { as 'being there' with others }\end{array}$ & $\begin{array}{l}\text { Dialogical and non- } \\
\text { dychotomic }\end{array}$ & Inclusion and empathy \\
\hline
\end{tabular}

